\title{
ProfECIAS APOCALÍPTICAS NA COSMOLOGIA MBYA-GUARANI
}

\author{
Rodrigo Luiz Simas de Aguiar ${ }^{1}$
}

\begin{abstract}
RESUMO
As profecias apocalípticas representam um importante aspecto da cosmologia guarani. Como parte inerente da religiosidade, os mitos de destruição do mundo se mostram importantes elos que se entrelaçam com outros elementos cosmológicos na construção do ethos mbya-guarani. A análise deste conteúdo mitológico apocalíptico pode revelar outras variáveis envolvidas na relação do indígena com 0 entorno. Abordar uma análise desta natureza é justamente o que propõe o presente artigo.
\end{abstract}

Palavras-chave: Mitologia. Cosmologia. Guarani. Ethos.

\section{APOCALYPTIC PROPHECIES IN MBYA-GUARANI COSMOLOGY}

\section{ABSTRACT}

Apocalyptic prophecies represent an important aspect of Guarani cosmology. As an inherent part of religiousness, world destruction myths are important bonds that intertwine with other cosmological elements in the construction of the ethos Mbya-Guarani. The analysis of this apocalyptic mythological content may reveal other variables involved in the relationship between indigenous people and the environment. Approaching this kind of analysis is precisely what this article proposes.

Keywords: Mythology. Cosmology. Guarani. Ethos.

\footnotetext{
${ }^{1}$ Professor Doutor da Faculdade de Ciências Humanas e do Programa de Pós-graduação em Antropologia da Universidade Federal da Grande Dourados, Brasil. rodrigoaguiar@ufgd.edu.br
} 


\section{INTRODUÇÃO}

cosmologia, enquanto categoria de estudo etnológico, possibilita ao antropólogo
um vasto campo de trabalho, permitindo uma imersão privilegiada no universo
simbólico dos grupos investigados. Dedicando-se ao registro da natureza cosmológica de determinado grupo étnico, o antropólogo acessa um conteúdo sóciocultural produtivo, que viabiliza uma dilatada gama de análises, correlações e interpretações. E isso não é de se estranhar, haja vista que a cosmologia é resultado das construções coletivas que têm por função contribuir com a teia de elementos simbólicos que conferem sentido ao mundo dos atores sociais em questão. Dessa forma, os elementos simbólicos devem ser analisados como um códice, por meio do qual 0 antropólogo pode, a partir da interpretação, compreender como estas etnias pensam seu entorno social e natural.

Ao interpolar a análise das categorias descritas a partir do universo simbólico dos grupos étnicos com os pressupostos da antropologia interpretativa de Geertz, é possível compreender que a cosmologia se manifesta através de uma série de contornos simbólicos que compõem um repertório elaborado para conferir um sentido de mundo (GEERTZ, 2001). Porém, este repertório é tão diverso entre distintos grupos étnicos, que a análise das categorias que o compõe pode resultar em trabalho tão difuso quanto minucioso. É aí que aparece a relevância dos estudos das representações cosmológicas para a compreensão de outras estruturas da sociedade, pois é inegável que a cosmologia, enquanto parte inerente de uma estrutura social, afeta as outras variáveis que compõem o sistema como um todo. Elementos cosmológicos se comportariam como estruturas nucleares, que irradiam sua influência sobre outros aspectos da vida social, numa cadeia concêntrica.

Entretanto, para estabelecer uma análise das teias de significantes e significados atrelados ao campo da cosmologia, o antropólogo precisa conhecer o idioma cultural do grupo estudado. Umberto Eco (1988) assevera que os signos que compõem este repertório simbólico são moldados no interior de uma cultura e só atingem o fim para 0 qual foram projetados junto àqueles que compreendem com plenitude 0 idioma cultural em questão. Daí a importância da etnografia como caminho para atingir esse estado de conhecimento.

Thompson (1995) vem propor que os seres humanos conferem significação também às ações sociais. Ou seja, a cultura imaterial é paradoxalmente responsável por dotar de significantes seus próprios elementos simbólicos, cabendo ao antropólogo identificar em meio ao material etnográfico as estruturas de significantes que outorgam 0 ordenamento indispensável para dar sentido ao universo nativo.

Tomando por base as considerações acima apresentadas, este artigo tem por objetivo elaborar uma análise das narrativas apocalípticas que integram o conteúdo 
cosmológico dos Mbya Guarani. Para tanto, além da literatura disponível, será utilizado material etnográfico levantado por ocasião de uma pesquisa antropológica por mim empreendida no ano de 2003 entre os indígenas dessa etnia, em especial aqueles assentados na aldeia de Massiambú, litoral de Santa Catarina².

\section{A COSMOLOGIA E OS POVOS GUARANI-FALANTES}

Em se tratando de povos indígenas, é importante destacar que entre muitas etnias são formadas categorias cosmológicas que regulam a relação entre seres humanos e não-humanos, em que ambos compartilham atributos que no mundo ocidental seriam exclusivos dos humanos, tema explorado pela teoria do perspectivismo ameríndio (VIVEIROS DE CASTRO, 2002). Nas próprias palavras de Viveiro de Castro, 0 perspectivismo se refere à "concepção, comum a muitos povos do continente, segundo a qual o mundo é habitado por diferentes espécies de sujeitos ou pessoas, humanas e nãohumanas, que 0 apreendem segundo pontos de vista distintos." (VIVEIROS DE CASTRO, 1996, p. 115). Contudo, para poder estabelecer um recorte temático, centrei a discussão deste artigo nas profecias apocalípticas.

Entre os Mbya, o discurso religioso está significativamente atrelado aos mitos de criação e destruição do mundo. As narrativas mitológicas se equilibram entre a gênese e 0 apocalipse para conferir significação e equilíbrio à vida social. No caso, o presente artigo tem por objeto as profecias apocalípticas em virtude da influência que os mitos de destruição do mundo exercem sobre a coletividade Guarani. Mesmo entendendo que muitos grupos situados como Guarani se apresentem como etnias específicas, as etnografias revelam importantes continuidades no plano do discurso cosmológico e das narrativas míticas (AGUIAR; PEREIRA, 2012), o que dá sustentação à análise aqui apresentada.

Percebo que estabelecer analogias entre diferentes grupos guarani falantes não é tão simples, haja vista as divergências entre os pesquisadores no que tange à etnohistória dos povos Guarani e incluso a assimetrias observadas no interior das etnias contemporâneas. Pensar as populações de origem Tupi-guarani como um grande corpo coeso e uníssono - ou monolítico como alguns preferem - atualmente é um raciocínio

\footnotetext{
${ }^{2}$ No que diz respeito às releituras de dados etnográficos, gostaria de tecer algumas considerações. A partir da releitura de dados registrados pelo antropólogo no trabalho de campo e o posterior cruzamento com tendências antropológicas modernas é possível extrair reflexões de destacado valor para a antropologia. Como bem coloca Cardoso de Oliveira (2006), o texto antropológico final, como produto acadêmico, resulta de um ir e vir entre o registro etnográfico e os conceitos básicos constitutivos da disciplina. Seria 0 que Geertz (2001) classifica como o being there e o being here. Às vezes leva tempo para 0 antropólogo dominar com aptidão essa transumância entre caderno etnográfico e pressupostos teórico-metodológicos, por isso a necessidade de releituras.
} 
sujeito a críticas. André Luiz Ramos Soares (2012), em seu artigo "Pelo fim do Krankenstein Guarani", discute a construção histórica da denominação "Grupo Guarani" que teve por base, em muitos casos, fragmentos de informações que desconsideravam diferenças espaciais, temporais e étnicas. Contudo, no que diz respeito aos grupos guarani-falantes atuais, a constatação de permanências no discurso cosmológico faz com que as analogias aqui estabelecidas não sejam ideias lançadas ao vazio, mas sim se sustentem pelo fato de estes grupos compartilharem uma matriz mítico-religiosa altamente persistente. Essa persistência de núcleos cosmológicos e religiosos compartilhados por diversos grupos guarani se percebe ao analisar etnografias produzidas em diferentes temporalidades e espacialidades ${ }^{3}$.

0 contexto mitológico, equalizado entre gênese e apocalipse, confere à vida ordinária a qualidade de prisma distorcido, que mal dá conta em revelar a essência original de todas as coisas, pois essa essência está presente de maneira integral única e exclusivamente no paraíso mítico, o yvy marae'y. De início percebe-se uma relação interessante entre a cosmologia guarani e o mito da caverna de Platão. Analogamente ao mito da caverna, para os Guarani os seres que habitam a terra são apenas uma imagem tênue, ou seja, o reflexo distorcido daqueles originais que habitam o paraíso. Esta condição de virtualidade da vida terrena pode ser constatada nas narrativas registradas por León Cadogan sobre yvy tenondé, a terra primitiva (CADOGAN, 1954).

Paradoxalmente, os Mbya constroem uma narrativa que confere acessibilidade ao paraíso, dotando de sentido a vida material. A existência do ser humano ordinário, desta forma, ganha significado no momento em que se estabelece uma vinculação direta entre o acesso ao plano divino e a observação dos preceitos religiosos. Munido da possibilidade de ingressar no yvy marae'y ainda em vida, o Mbya recorre à religiosidade como pivô fundamental de sua sociedade, conferindo estabilidade e coerência aos elementos estruturais que configuram a organização social.

Não obstante, as mazelas impostas ao grupo em decorrência das relações danosas com a sociedade nacional, cuja raiz remete aos tempos coloniais, adquirem significação

\footnotetext{
${ }^{3}$ Principais etnografias sobre Guaranis produzidas até a primeira metade do século XX:

Curt Nimuendajú - estima-se o início de suas atividades de campo entre os Apapocuva em 1906 e sua primeira publicação sobre o grupo se deu em 1914; Leon Cadogan - suas primeiras experiências com os Mbya datam da década de 1920; Egon Schaden - suas produções em nível de pós-graduação se deram na década de 1940; Bartomeu Meliá - iniciou sua etnografia na década de 1954 e publicou por primeira vez em sua tese de 1969 .

Da segunda metade do século XX até os dias atuais houve considerável ampliação do conhecimento acerca dos grupos guarani-falantes com publicação de diversas etnografias, sendo que aqui destaco algumas: Pierre Clastres [1974] (1990), Maria Inês Ladeira (1992), Aldo Litaiff [1991] (1996 e 1999), Francisco Noelli (1993), Antonio Brand (1997), Levi Marques Pereira (1999 e 2004), Deise Lucy Montardo (2002), Maria Dorothea Post Darella (2004), Valéria Soares de Assis (2006).
} 
na estrutura cosmológica. A dicotomia yvy marae'y (plano divino) em oposição a yvy mbae meguá ('terra da maldade', plano material, terreno) vai estabelecer as dinâmicas sociais de relacionamento com os demais grupos étnicos. 0 insucesso da condição humana passa a ser relacionado com a ação do Juruá - o homem branco. Novo par de oposição aparece na teia mitológica: o Mbya como objeto da criação de Nhanderu - 0 Deus Supremo - e o Juruá como engenho de Anhá - o demônio.

$\mathrm{Na}$ condição de mitema, este insucesso da humanidade deve ser reparado, sendo que para tanto o apocalipse é uma forma digerível pelo grupo. 0 núcleo básico do mito de destruição seria a relação entre a imperfeição da condição terrenal humana e a busca pelo modo perfeito, o tekó porã (AGUIAR; PEREIRA, 2012), cujo modelo ideal é aquele presente de forma integral somente no paraíso. Trata-se da virtualidade corruptiva e punível da yvy-mbae meguá (terra da maldade) em oposição à divindade das formas integrais do yvy-maraey. A relação ambígua entre tekó porã (modo ideal) e tekó vaí (modo imperfeito) terá implicações diretas nas regras de conduta social e na definição dos comportamentos sociais valorizados ou considerados inapropriados para a vida em comunidade (AGUIAR; PEREIRA, 2012). Diante do dilema entre virtualidade terrenal e integralidade do paraíso as mitologias apocalípticas adquirem sua condição de extrema relevância religiosa. Esta linha de raciocínio vem de encontro à idéia de Melià (1990) de que a busca por yvy-maraey nunca esteve desligada da vida social, mas é a condição realista da economia de reciprocidade. Ou seja, tão importante quanto o papel cosmológico da transposição mágica do corpo físico para o paraíso mítico, é o efeito que a terra sem males tem sobre a ordem social. Trata-se da cosmologia como mecanismo de propulsão da vida em comunidade.

\section{O DIAGRAMA COSMOLÓGICO E OS PARES DE OPOSIÇÃO}

Para os Mbya do litoral de Santa Catarina ${ }^{4}$, o marco divisor entre o mundo ordinário e a morada do deus criador - Nhanderu - é o oceano. Ou seja, yvy marae'y está indubitavelmente situado a leste. A porção oriental, para além do Oceano Atlântico, só pode ser a morada de Nhanderu, pois é de lá que o sol vem todos os dias para iluminar a terra. 0 sol, que em guarani recebe o nome de Kuaray, é uma importante divindade responsável pela manutenção da vida na terra e os rituais diários de reza servem para agradecer e estimular seu retorno todos os dias. Conforme registrado por Deise Lucy Montardo, o sol "é um xamã, e ele canta e toca seus instrumentos durante 0 dia. Durante a noite os homens são os responsáveis por tocar, cantar e dançar, o que tem que fazer para manter o mundo, a vida na terra" (MONTARDO, 2002, p. 11). Caso os

\footnotetext{
${ }^{4}$ Notei a reprodução desse discurso entre informantes de três aldeias visitadas na ocasião: Massiambu, Imaruí e Morro dos Cavalos.
} 
homens deixem de rezar, o sol poderá não mais retornar, o que provocaria o colapso da terra.

Em oposição ao paraíso está o oeste, a morada de Anhá. Desde o oeste o demônio se eleva para trazer à terra suas articulações malévolas, cujo principal objetivo é impelir sofrimento à humanidade em geral e aos Guarani em particular. A estrutura do mito se completa: leste: paraíso: Nhanderu: Mbyá: oeste: destruição: Anhá: Juruá. Os discursos sobre o paraíso e sobre a terra do mal se consolidam dentro desta lógica estrutural.

0 paraíso também assume contorno político na verbalização dos líderes religiosos. Pajés, inspirados por suas visões, afirmam ter visto o paraíso mítico, onde encontraram os heróis mitológicos que conseguiram transpor as barreiras que separam os dois mundos. Ao se apropriar deste discurso, o líder espiritual fundamenta seu poder político no interior do grupo. Ao mesmo tempo, sendo o pajé o nexo entre mundo ordinário e mundo espiritual, torna-se o principal praticante da medicina, haja vista que as enfermidades derivam da ação dos maus espíritos sobre os vivos. Portanto, o líder religioso é detentor de elevado prestígio ante o grupo. Somente um messias pode se igualar a um pajé em influência religiosa, motivo pelo qual de tempos em tempos emergem reivindicações desta natureza. Caso seja reconhecido pela coletividade como 0 eleito, caberá ao messias transportar seus seguidores ao paraíso por meio de uma longa caminhada que testará as qualidades religiosas do grupo. Na fala de um informante ${ }^{5}$ a caminhada rumo ao paraíso é descrita da seguinte forma:

Por que pelo que a gente sabe, Nhanderu, não fica lá em cima, fica no mundo, no outro lado do mundo. Ele tem uma morada aqui, só que é uma terra que não é que nem aqui, mas dá para o Guarani chegar lá caminhando. Até que a gente sabe, não muito que passou para lá, mas quatro, cinco pessoas que já foram. Na verdade tem que Nhanderu dizer para nós, iluminar nosso caminho para nós passarmos para o outro lado do mundo, desce o mar aqui e fica por aqui assim [apontando para a canela] e aí vai andando. Agora, só que para isso tem que rezar muitos anos.

A partir deste e de outros relatos identifica-se o modelo de cosmovisão que confere forma ao universo, construído mentalmente em uma estrutura bidimensional que se sobrepõe aos pontos cardeais: o paraíso e morada do Criador a leste, no além-mar; e o oeste como território de Anhá, desde onde se originam os males que assolam a humanidade. Deste modo, para o Guarani existe um único caminho a ser seguido: uma marcha a leste - normalmente simbólica, mas em alguns casos inclusive física guiada pelo corpo mitológico sagrado, que Cadogan transcreveu baixo o título de

\footnotetext{
${ }^{5}$ Ex-cacique que se converteu em professor na aldeia de Massiambú.
} 
nhe'eng porá tenondé, as "primeiras palavras formosas" (CADOGAN, 1953a; 1953b; 1954). Quando a marcha é transferida para o sentido figurado, aquele que preserva a cultura e os ensinamentos divinos está seguindo o caminho a leste.

Por fim, completando o diagrama bidimensional da cosmovisão, tudo aquilo que está ao norte ou ao sul configuram distrações que visam tirar o Guarani do caminho, distrações essas que na maior parte do tempo são engenhos de Anhá. A destruição do mundo, logicamente, viria do oeste, da terra de Anbá. Sendo o juruá (o homem branco), uma das fontes do sofrimento impelido aos indígenas, na cosmologia mbya ele aparece associado à figura de Anhá e não raramente portador das ações que darão início ao apocalipse.

Figura 1 - Tormentos operados por $A n b \hat{a}^{6}$

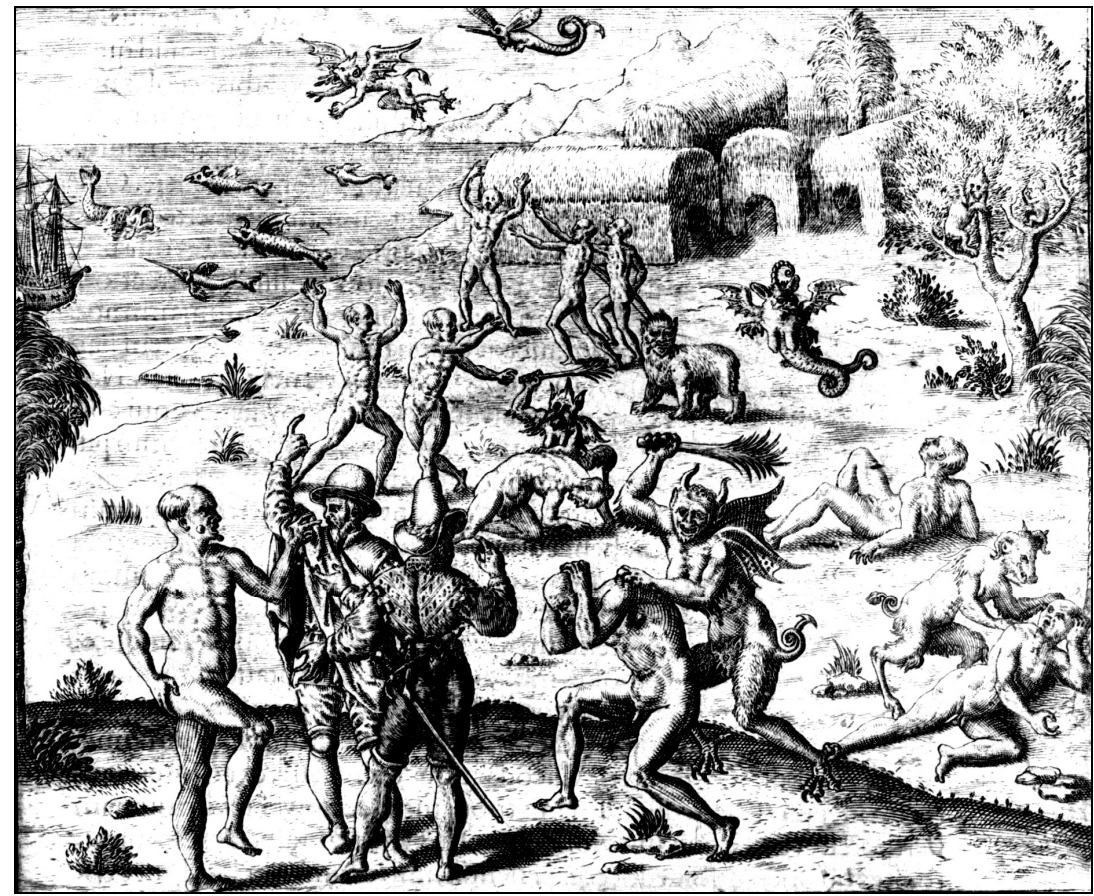

Fonte: De Bry (1592).

Os Mbya sustentam que o mundo já foi destruído e recriado. A primeira terra, Yvy Tenondé, foi destruída por Nhanderu ao enviar um grande dilúvio, e tal destruição

${ }^{6}$ Acervo da Biblioteca Histórica da Universidade de Salamanca. Reprodução digital autorizada. 
procedeu do desenvolvimento do lado animal do espírito Guarani, onde o fato culminante foi o incesto decorrente do desejo que Karai Jeupié nutria pela irmã de seu pai (CADOGAN, 1946; CLASTRES, 1990). A segunda terra, Yvy Pyahú, é onde se vive atualmente. Os constantes sofrimentos vividos nesta terra nova fizeram com que a mesma recebesse a alcunha de Yvy Mba'e Megua (a terra da maldade). Como experiência que, a exemplo da primeira terra, não deu certo, a destruição seria 0 caminho mais adequado, lançando-se assim 0 amálgama que sustentará 0 apocalipse como variável que confere sentido de mundo para os Mbya. Seria a quebra da virtualidade da vida terrenal pelo apocalipse que propiciaria ao Guarani ascender à totalidade das coisas, convertendo-se no ser integral original.

De acordo com as profecias dos messias e pajés, o fim de Yvy Pyahú se processará por um cataclismo, enviado por Nhanderu. A destruição é decorrente da degeneração do ser humano, que ao assumir seu lado mais animal e se desconectar do mundo espiritual, deve ser punido, a exemplo do que ocorreu com Yvy Tenondé. São muitos os cataclismos relatados, bem como diversas as suas causas. 0 motivo mais comum a que se atribui a destruição do mundo é deslocamento do popygua, a vara insígnia que escora a terra, primeiramente relatado por Nimuendaju (1987). Outra possível origem do apocalipse estaria em um eclipse, onde baixo escuridão total feras seriam liberadas para devorar os humanos (AGUIAR, 2003). Entre estas feras estaria o ojepotá, figura mitológica parte homem parte onça que representa a conseqüência punitiva para aquelas pessoas que apresentam desvios de conduta e personalidade (AGUIAR, 2003; AGUIAR; PEREIRA, 2012). Outra importante fera responsável por conduzir o mundo à destruição teria a forma de um morcego gigante comedor de gente.

\section{DECOMPONDO A ESSÊNCIA DOS MITOS}

Ao decompor a essência dos mitos de destruição do mundo entre os Mbya Guarani, chega-se a alguns núcleos básicos que alimentam o sistema. Primeiramente, entende-se que o fim se dará por meio de um processo de reivindicação legítima do cosmos sobre o patrimônio ecológico herdado "incondicionalmente", ou seja, as varas insígnias que sustentam a terra se deslocarão, provocando o colapso do globo terrestre tido na mitologia como entidade; ou ainda pela consolidação do lado obscuro da humanidade materializado na forma de eclipse total. Também aparecem nos discursos 0 fogo e a água, tidos como elementos naturais purificadores, evocando a necessidade de assepsia espiritual. Num segundo momento, a consolidação do apocalipse se sustenta por meio da sobrepujança da animália, que vence o homem e o devora. Em todo caso,

\footnotetext{
${ }^{7}$ A união entre tia paterna e sobrinho é tida entre diversas sociedades Guarani como um grande tabu, uma prática incestuosa. Notou-se a persistência de tal tabu entre os Mbya de Massiambu.
} 
trata-se do velho dilema ético do homem lutando contra seu lado animalesco. Ao alimentar 0 animal interior, o homem será conduzido à perdição. Levi Marques Pereira em parte transfere a ideia de uma luta interior para uma condição de resposta social, uma tentativa do Guarani de tematizar seu destino. Segundo Pereira, o apocalipse, bem como o profetismo a este relacionado, refletem o inconformismo dos Guarani em se submeter à vida terrena, apegando-se assim ao ideal de divinização dos homens e a superação da condição da vida em sociedade (PEREIRA, 1999). Contudo, independentemente da condição do mito - modelo filosófico de luta interior ou modelo social de tematização do destino - 0 tema da destruição do mundo deita suas raízes em meio aos aspectos de regulação das ações coletivas.

Como diferenciar na cosmologia mbya os eclipses até hoje presenciados pelo grupo daquele derradeiro, que traria destruição à terra? Para equilibrar a equação da estrutura, o grupo tece o discurso de que os eclipses que já ocorreram seriam obra de juruá, porque alguns, segundo eles, já vivem na lua - referindo-se às alunissagens feitas pelos estadunidenses - e os que lá habitam têm grande poder. "Só que eclipse de juruá só acontece em alguns lugares, não em todo o mundo. 0 eclipse de Nhanderú vai ser em todos os lugares da terra, deixando tudo quanto é país em escuridão total e todas as pessoas vão morrer", completa um informante de Massiambu.

A virada de milênio foi combustível para predições apocalípticas em um número sem fim de sociedades. Entre os Mbya, o ano 2000 seria o profético, quanto Nhanderu enviaria o cataclismo que consumiria Yvy Piahú. Essa crença na destruição do mundo por ocasião da virada de milênio também foi constatada por Aldo Litaiff (1996), no final da década de 1980, em seus trabalhos de campo na aldeia de Bracui, em Angra dos Reis, litoral do Rio de Janeiro. 0 processo de destruição é semelhante, com escuridão total, porém, para os Mbya de Bracui, a punição é culminada com fogo, que mata a todos. 0 fogo, além da condição de assepsia espiritual anteriormente mencionada, no caso de Bracui como o próprio Litaiff destaca (1996, p. 116) guarda relação com a Usina Nuclear Angra dos Reis. Tal fato me leva a sustentar que particularidades locais e regionais influenciam o processo de formação dos contornos simbólicos que compõem 0 repertório cosmológico, conforme assinalado no começo deste artigo. A essência mitológica é a mesma, ou seja, o conteúdo profundo pouco se altera, entretanto, marcos simbólicos locais são incluídos nas narrativas para trazer sentido ao mundo dos atores sociais imersos naquele espaço em questão.

Geertz propõe que os símbolos sagrados funcionam para sintetizar o ethos de um povo, adaptado ao estado de coisas atual que a cosmovisão descreve (GEERTZ, 1989). Seria a cataclismologia parte integrante do ethos guarani? Muitos autores apontam que as mitologias apocalípticas são uma predileção quase obsessiva entre diversos grupos Guarani (AGUIAR, 2003; MELİ̀, 1990; NIMUENDAJU, 1987; SCHADEN, 1976). Novamente recorre-se a Geertz para analisar a questão. A visão de mundo de um 
determinado grupo torna-se emocionalmente convincente por ser apresentada como uma imagem de um estado de coisas verdadeiro, ajustando as ações humanas a uma ordem cósmica imaginada (GEERTZ, 1989). Se o mito é um símbolo em forma de relato (ESPINA BARRI0, 1997), a mitologia apocalíptica guarani é uma expressão simbólica dotada de significantes que ajusta a religiosidade às novas realidades sócio-culturais, exigindo do grupo esta adaptação de sua cosmologia. Diante da inflexão do conteúdo mitológico essencial, essas novas realidades são acomodadas na forma de contornos simbólicos, como visto. Para Levi Strauss (2004) a cadeia mitológica nasce de um corpo multidimensional, onde as partes centrais se sustentam e persistem por representarem a ordem, ao passo em que na periferia reinaria confusão e incerteza. Se concordarmos com Levi Strauss, essa incerteza e confusão da periferia é o que permite que novos contornos simbólicos sejam delineados, admitindo a inserção de conteúdos contemporâneos sem, contudo, afetar a essência de seu núcleo - ou seja, sem abalar a ordem que traz estabilidade à vida social.

\section{Palavras Finais}

Indiscutivelmente, as duras penas impostas às sociedades tradicionais em decorrência da expansão das frentes econômicas, numa política de ajuste dos modos de produção de larga escala à "nova" realidade globalizada, trouxeram significativas transformações negativas no modo de vida destes grupos, hoje ocupando uma posição marginal na sociedade nacional. A prova disso é a indisponibilidade de terras e os decorrentes processos reivindicatórios que se avolumam na estrutura judiciária. A diminuição dos espaços disponíveis em muitos momentos foi processada pelo espolio das terras tradicionalmente ocupadas por populações indígenas. Desta forma, ao aplicar a realidade guarani ao pressuposto teórico de Geertz, entende-se que outros contornos mitológicos são delineados a fim de tornar digerível pelo grupo esta nova ordem cosmológica que a ele se apresenta, acarretando uma visão soturna da humanidade e a necessidade do apocalipse para trazer ordem ao caos imposto às populações indígenas pelo atual arranjo político. Em síntese, esta faceta cataclísmica que se eleva no interior do ethos mbya guarani pode, outrossim, ser uma resposta cultural para trazer sentido ao mundo tal qual se apresenta na contemporaneidade, o resultado da busca por equilíbrio na equação da vida social.

A convivência com novas referências oriundas da sociedade nacional, ao mesmo tempo em que exige explicações para situações até então excepcionais, também fornece novos recursos e ferramentas analíticas para pensar o mundo, recursos utilizados não para alterar a essência cosmológica primordial, mas para acrescentar contornos e trazer equilibrio. Criativamente, os Guarani mobilizam seus modelos cosmológicos para produzir explicações acerca de um mundo transformado. Permanece sempre a 
recorrência dos temas apocalípticos, demonstrando tratar-se de um mote central neste modelo cosmológico.

\section{AgRADECIMENTOS}

Ao amigo Levi Marques Pereira pela atenção dedicada e pelas sugestões para 0 aprimoramento do artigo. Aos colegas das aldeias de Massiambu, Imaruí e Morro dos Cavalos, sempre dispostos a compartilhar seus extensos conhecimentos. Também aos pareceristas que com suas ponderações permitiram aperfeiçoar o conteúdo do artigo e à Revista Mediações pela oportunidade de publicação.

\section{REFERÊNCIAS}

AGUIAR, Rodrigo Luiz Simas de. Los Mbya en el litoral de Santa Catarina, Brasil. 2003. Tese (Doutorado em Antropologia) - Universidade de Salamanca, Salamanca, 2003.

AGUIAR, Rodrigo Luiz Simas; PEREIRA, Levi Marques. 'Religion, dualité de 1 âme et représentations du tekó porã et du tekó vai chez les peuples Guarani!'. Anthropologica Revue de la Société Canadienne d'Anthropologie, Ottawa, v. 54, p. 309-318, 2012.

ASSIS, Valéria Soares de. Dádiva, mercadoria e pessoa: as trocas na constituição do mundo social Mbya-Guarani. 2006. Tese (Doutorado em Antropologia) - Universidade Federal do Rio Grande do Sul, Porto Alegre, 2006.

BRAND, Antonio. 0 impacto da perda da terra sobre a tradição Kaiowá/Guarani: os difíceis caminhos da palavra. 1997. Tese (Doutorado em História) - Pontifícia Universidade Católica do Rio Grande do Sul, Porto Alegre, 1997.

CADOGAN, León. Las tradiciones religiosas de los Mbyá-Guarani del Guairá. Revista de la Sociedad Cientifica del Paraguay, vol VI-I. Asunción, 1946.

. Maino i reko ypy kue, las primitivas costumbres del Colibrí. Revista de Antropologia, São Paulo, v. 1, n. 1, p. 35-42, 1953a.

'Ayvu Rapyta': el fundamento del lenguage humano. Revista de Antropologia, São Paulo, v. 1, n. 2, p. 123-132, 1953 b.

. Yvy Tenonde, la primera tierra. Revista de Antropologia, São Paulo, v. 2, n. 1, p. 37-46, 1954.

CLASTRES, Pierre. A fala sagrada: mitos e cantos sagrados dos índios Guarani. Campinas: Papirus Editora, 1990. 
DARELLA, Maria Dorothea Post. Ore roipota yvy porá: "nós queremos terra boa": territorialização Guarani no litoral de Santa Catarina - Brasil. 2004. Tese (Doutorado em Ciências Sociais) - Pontifícia Universidade Católica, São Paulo, 2004.

DE BRY, Theodor. Americae. Frankfurt: Officina Theodori de Bry, 1592.

ECO, Umberto. Signo. Barcelona: Editorial Labor, 1988.

ESPINA BARRI0, Angel Baldomero. Freud y Levi-Strauss: influencias, aportaciones e insuficiencias de las antropologías dinámica y estrutural. Salamanca: Universidad Pontificia de Salamanca, 1997.

GEERTZ, Clifford. A interpretação das culturas. Rio de Janeiro: LTC, 1989.

. O saber local. Petrópolis: Vozes, 2001.

LADEIRA, Maria Inês. O caminhar sob a luz: o território Mbya a beira do oceano. 1992. Dissertação (Mestrado em Antropologia) - Pontifícia Universidade Católica de São Paulo, São Paulo, 1992.

LEVI-STRAUSS, Claude. O cru e o cozido. Mitológicas 1. São Paulo: CosacNaify, 2004.

LITAIFF, Aldo. As divinas palavras: identidade étnica dos Guarani-Mbyá. Florianópolis: Editora da UFSC, 1996.

Les Fils du Soleil: mythes et pratiques des Indiens Mbya-Guarani du littoral du Brésil. 1999. Tese (Doutorado) - Universidade de Montreal, Quebec.

MELIÁ, Bartomeu. A terra sem mal dos Guarani: economia e profecia. Revista de Antropologia da USP, São Paulo, n; 33, p. 33-46, 1990.

MONTARD0, Deise Lucy. Através do Mbaraká: musica e xamanismo Guarani. 2002. Tese (Doutorado em Antropologia Social) - Faculdade de Filosofia, Letras e Ciências Humanas, Universidade de São Paulo, São Paulo. 2002.

NIMUENDAJU, Curt. As lendas da criação e destruição do mundo como fundamentos da religião dos Apapocúva-Guarani. São Paulo: HUCITEC, 1987.

NOELLI, Francisco Silva. Sem Tekóba não há Tekó. 1993. Dissertação (Mestrado em Antropologia) - Pontifícia Universidade Católica do Rio Grande do Sul, Porto Alegre.

OLIVEIRA, Roberto Cardoso. 0 trabalho do antropólogo. São Paulo: UNESP, 2006.

PEREIRA, Levi Marques. Imagens Kaiowá do sistema social e seu entorno. 2004. Tese (Doutorado em Antropologia) - Universidade de São Paulo, São Paulo. 2004.

. Parentesco e organização social Kaiowá. 1999. Dissertação (Mestrado em Antropologia) - Instituto de Filosofia e Ciências Humanas, UNICAMP, Campinas. 1999. 
SCHADEN, Egon. A origem do fogo na mitologia Guarani. In: Leituras de etnologia brasileira. São Paulo: Companhia Editora Nacional, 1976. p. 306-314.

SOARES, André Luiz Ramos. Pelo fim do Frankenstein Guarani. Revista Diálogos, Brasília, v. 16, n. 2, p. 767-790, 2012.

THOMPSON, John B. Ideologia e cultura moderna. Petrópolis: Vozes, 1995.

VIVEIROS DE CASTR0, Eduardo. A inconstância da alma selvagemi: e outros ensaios de antropologia. São Paulo: CosacNaify, 2002.

Os pronomes cosmológicos e o perspectivismo ameríndio. Mana, Rio de Janeiro, v. 2, n. 2, p. 115-144, 1996. 